\title{
Radiation Damage Investigation on Certain Alternative Fluids in a Hybrid System by Using MCNPX Monte Carlo Radiation Transport Code
}

\author{
M. GÜNAY* \\ İnönü University, Science and Art Faculty, Physics Department, Malatya, Turkey
}

\begin{abstract}
In this study, the effect of the radiation damage of spent fuel-grade plutonium content was investigated in the structural material of a designed fusion-fission hybrid reactor system. In this study, the molten salt-heavy metal mixtures 99-95\% $\mathrm{Li}_{20} \mathrm{Sn}_{80}-1-5 \%$ SFG-Pu, 99-95\% $\mathrm{Li}_{20} \mathrm{Sn}_{80}-1-5 \%$ SFG-PuF 4 , and 99-95\% $\mathrm{Li}_{20} \mathrm{Sn}_{80}-1-5 \%$ SFG-PuO 2 were used as fluids. The fluids were used in the liquid first-wall, blanket and shield zones of the designed hybrid reactor system. Four centimeter thick 9Cr2WVTa ferritic steel was used as the structural material. Proton, deuterium, tritium, He-3 and He-4 gas production rates are the parameters of radiation damage. In this study, damage to the total structural material and each $1.0 \mathrm{~cm}$ thickness thereof was measured as a function of radiation energy, using the selected fluid rates, for 30 full power years (FPYs). Three-dimensional analyses were performed using the most recent MCNPX-2.7.0 Monte Carlo radiation transport code and the ENDF/B-VII.0 nuclear data library.
\end{abstract}

DOI: 10.12693/APhysPolA.128.B-113

PACS: 28.52.-s, 28.52.Av

\section{Introduction}

The hybrid reactor system, in which nucleus fusion and fission events can be operated simultaneously, was developed to obtain more energy and nuclear fuel, decrease the waste amounts in storage areas, recover transuranic elements in used fuels through reprocessing, and render fission products harmless. When $\mathrm{D}-\mathrm{T}$ fuel enters into a fusion reaction in hybrid reactor systems, $14.1 \mathrm{MeV}$ fusion neutrons and $3.5 \mathrm{MeV}$ alpha particles are released. The plasma is surrounded by a wall of fertile material $\left({ }^{232} \mathrm{Th},{ }^{238} \mathrm{U}\right)$. Thus, the high-energy $14.1 \mathrm{MeV}$ fusion neutrons that are emitted from the plasma react with the fertile materials, resulting in fissile $\left({ }^{233} \mathrm{U},{ }^{239} \mathrm{Pu}\right)$ materials [1-4].

A substantial amount of spent fuel grade (SFG) plutonium $(\mathrm{Pu})$ from current nuclear reactors has been stored for future use. Isotopic distribution of spent fuelgrade plutonium is $2.4 \%{ }^{238} \mathrm{Pu}, 58.5 \%{ }^{239} \mathrm{Pu}, 24 \%{ }^{240} \mathrm{Pu}$, $11.2 \%{ }^{241} \mathrm{Pu}$, and $3.9 \%{ }^{242} \mathrm{Pu}[5]$. SFG-Pu is valuable for its use as a fissile material, but it is dangerous when misused. With this purpose, radioactive materials with a plutonium additive were used in designed hybrid reactor system in this study to reduce the amount of spent fuel-grade plutonium.

In the designed hybrid reactor system, $\mathrm{Li}_{20} \mathrm{Sn}_{80}$ was chosen for the molten salt. Beryllium (Be) is used as a neutron multiplier. The $\mathrm{Be}(\mathrm{n}, 2 \mathrm{n})$ reaction has an effective threshold of $2.5 \mathrm{MeV}$, above which the cross-section value is 0.5 barns [6]. In this study, a Be zone with a

\footnotetext{
*e-mail: mehtap.gunay@inonu.edu.tr
}

thickness of $3 \mathrm{~cm}$ was used between the liquid first-wall and the blanket. In this study, 9Cr2WVTa ferritic steel was chosen as a structural material of the reactor system.

The hybrid reactor system based on magnetic fusion energy (MFE) was designed using the ENDF/BVII.0 nuclear data library and $99-95 \% \mathrm{Li}_{20} \mathrm{Sn}_{80}-1-5 \%$ SFG-Pu, 99-95\% $\mathrm{Li}_{20} \mathrm{Sn}_{80}-1-5 \%$ SFG-PuF 4 , and 99$95 \% \mathrm{Li}_{20} \mathrm{Sn}_{80}-1-5 \% \mathrm{SFG}-\mathrm{PuO}_{2}$ as the fluids. The fluids were used in the liquid first-wall, blanket and shield zones of the hybrid reactor system. The radiation damage, as a function of energy, to the total structural material and each $1.0 \mathrm{~cm}$ thickness thereof, was calculated using the most recent version MCNPX-2.7.0 Monte Carlo code for a full power operation period of 30 years (FPYs) in structural material of the designed system.

\section{Method}

\subsection{Geometry description}

The radial structure of the hybrid reactor system is shown in Table I. The hybrid reactor system is toroidal. The radius of the torus is $552 \mathrm{~cm}$. The fast-flowing liquid first-wall is $2 \mathrm{~cm}$ thick, and the slow-flowing layer (blanket) is $50 \mathrm{~cm}$ thick. In this study, a Be zone with a thickness of $3 \mathrm{~cm}$ was used between the liquid first-wall and the blanket. A backing solid wall of $4 \mathrm{~cm}$ thickness and made of $9 \mathrm{Cr} 2 \mathrm{WVTa}$ ferritic steel follows the blanket zone. A shielding zone of $50 \mathrm{~cm}$ thickness (outboard) and $49 \mathrm{~cm}$ thickness (inboard) is located behind the backing solid wall for the outboard and inboard builds, respectively, and is assumed to have a structure-to-breeder (coolant) volume ratio of 60:40. The vacuum vessel wall is $2 \mathrm{~cm}$ thick and made of SS316LN stainless steel. The interior is $16 \mathrm{~cm}$ thick (inboard) and $26 \mathrm{~cm}$ thick 
(outboard) with the SS316LN stainless steel cooled with water by a structure-to-water ratio of 80:20 [7].

TABLE I

The radial build of the hybrid reactor system design.

\begin{tabular}{c|c|c|c}
\hline \hline \multicolumn{2}{c|}{ Inboard side } & \multicolumn{2}{c}{ Outboard side } \\
\hline Zone & $r[\mathrm{~cm}]$ & Zone & $r[\mathrm{~cm}]$ \\
\hline SS316LN & 276 & plasma & 667 \\
vacuum vessel $^{a}$ & 278 & SOL & 695 \\
SS316LN & 294 & liquid first wall $^{d}$ & 697 \\
GAP & 296 & Be $^{e}$ & 700 \\
shield $^{b}$ & 301 & blanket $^{d}$ & 750 \\
ferritic steel $^{c}$ & 350 & ferritic steel $^{c}$ & 754 \\
blanket $^{d}$ & 354 & shield $^{b}$ & 804 \\
Be $^{e}$ & 404 & GAP & 838 \\
liquid first wall & \\
SOL & 407 & SS316LN & 840 \\
plasma & 409 & vacuum vessel & 866 \\
\hline
\end{tabular}

${ }^{a} 80 \%$ SS316LN, 20\% $\mathrm{H}_{2} \mathrm{O} ;{ }^{b} 60 \%$ 9Cr2WVTa,

40\% (99-95\% $\mathrm{Li}_{20} \mathrm{Sn}_{80}-1-5 \%$ SFG-Pu,

99-95\% $\mathrm{Li}_{20} \mathrm{Sn}_{80}-1-5 \% \mathrm{SFG}_{4}-\mathrm{PuF}_{4}$,

99-95\% $\mathrm{Li}_{20} \mathrm{Sn}_{80}-1-5 \%$ SFG-PuO 2$) ;{ }^{c} 100 \%$ 9Cr2WVTa;

${ }^{d} 99-95 \% \mathrm{Li}_{20} \mathrm{Sn}_{80}-1-5 \%$ SFG-Pu,

99-95\% $\mathrm{Li}_{20} \mathrm{Sn}_{80}-1-5 \%$ SFG-PuF 4 ,

99-95\% $\mathrm{Li}_{20} \mathrm{Sn}_{80}-1-5 \%$ SFG-PuO $2 ;{ }^{e} 100 \%$ Be.

\subsection{Numerical calculations}

Nuclear reaction cross-sections can be obtained in three different ways: experimental measurement, theoretical calculation and evaluated nuclear data files (ENDFs). For wide ranges of energy, measuring the cross-sections for all of the isotopes in the periodic table is infeasible both physically and economically. Therefore, model calculations play an important role in the evaluation of nuclear data $[8,9]$.

The evaluated nuclear data file $\mathrm{ENDF} / \mathrm{B}$ was first developed in the USA in 1968. New versions were published periodically following large-scale investigations and additional research. ENDF/B-VII includes data from $10^{-11} \mathrm{MeV}$ to $20 \mathrm{MeV}$ for all isotopes and up to $150 \mathrm{MeV}$ for certain isotopes [10, 11].

The Monte Carlo method is generally preferred due to its success with three-dimensional complex geometry configurations of materials and physics problems using deterministic methods. This study was performed with neutron wall loadings of $10 \mathrm{MW} / \mathrm{m}^{2}$ and fusion power of $4000 \mathrm{MW}$.

\section{Conclusions}

The effects of the spent fuel-grade plutonium on the radiation damage parameters, such as proton, deuterium, tritium, He-3 and He-4 gas production rates, measured in atomic parts per million (appm) in the structural material, were investigated for fifteen different fluids.
The fluids were composed of $99-95 \% \mathrm{Li}_{20} \mathrm{Sn}_{80}$ with increasing mole fractions of heavy metals $1-5 \%$ SFG-Pu, SFG-PuF 4 , and $\mathrm{SFG}-\mathrm{PuO}_{2}$.

TABLE II

Proton production values in structure material for the mixture components $\mathrm{Li}_{20} \mathrm{Sn}_{80}$, SFG-Pu, SFG-PuF 4 , $\mathrm{SFG}-\mathrm{PuO}_{2}$ in the system.

\begin{tabular}{c|c|c|c}
\hline \hline \multirow{2}{*}{$\begin{array}{c}\text { Heavy metal } \\
\text { content }[\mathrm{mol} \%]\end{array}$} & \multicolumn{3}{|c}{ Proton production $(\mathrm{appm} / 30 \mathrm{FPY})$} \\
\cline { 2 - 4 } & $\mathrm{Pu}$ & $\mathrm{PuF}_{4}$ & $\mathrm{PuO}_{2}$ \\
\hline 1 & 317.47 & 310.52 & 370.31 \\
2 & 315.35 & 303.30 & 286.82 \\
3 & 312.67 & 295.82 & 284.99 \\
4 & 307.94 & 289.27 & 274.80 \\
5 & 307.89 & 277.75 & 269.46
\end{tabular}

TABLE III

As in Table II, but for deuterium.

\begin{tabular}{c|c|c|c}
\hline \hline \multirow{2}{*}{$\begin{array}{c}\text { Heavy metal } \\
\text { content }[\mathrm{mol} \%]\end{array}$} & \multicolumn{3}{|c}{ Deuterium production $(\mathrm{appm} / 30 \mathrm{FPY})$} \\
\cline { 2 - 4 } & $\mathrm{Pu}$ & $\mathrm{PuF}_{4}$ & $\mathrm{PuO}_{2}$ \\
\hline 1 & 7.85 & 7.71 & 9.10 \\
2 & 7.74 & 7.46 & 7.16 \\
3 & 7.63 & 7.22 & 7.01 \\
4 & 7.61 & 7.07 & 6.77 \\
5 & 7.53 & 6.81 & 6.61
\end{tabular}

TABLE IV

As in Table II, but for tritium.

\begin{tabular}{c|c|c|c}
\hline \hline \multirow{2}{*}{$\begin{array}{c}\text { Heavy metal } \\
\text { content [mol\%] }\end{array}$} & \multicolumn{3}{|c}{ Tritium production (appm/30 FPY) } \\
\cline { 2 - 4 } & $\mathrm{Pu}$ & $\mathrm{PuF}_{4}$ & $\mathrm{PuO}_{2}$ \\
\hline 1 & $2.959 \times 10^{-2}$ & $2.778 \times 10^{-2}$ & $3.073 \times 10^{-2}$ \\
2 & $2.648 \times 10^{-2}$ & $2.628 \times 10^{-2}$ & $2.869 \times 10^{-2}$ \\
3 & $2.594 \times 10^{-2}$ & $2.493 \times 10^{-2}$ & $2.371 \times 10^{-2}$ \\
4 & $2.590 \times 10^{-2}$ & $2.408 \times 10^{-2}$ & $2.251 \times 10^{-2}$ \\
5 & $2.566 \times 10^{-2}$ & $2.257 \times 10^{-2}$ & $2.284 \times 10^{-2}$
\end{tabular}

Tables II-VI show the total radiation damage parameters (appm/30 FPY), including proton, deuterium, tritium, He- 3 and He- 4 gas production rates, in the structural material for the fifteen different fluid ratios with increase of mole percentages of SFG-Pu, SFG-PuF 4 , and $\mathrm{SFG}-\mathrm{PuO}_{2}$. Tables II-VI show that the total radiation damage parameters in the structural material decreases with an increase in the heavy metals contents for the selected fluids. In Tables II, III and Table VI, this decrease in the proton, deuterium and He-4 production rates between the minimum and maximum contents of the heavy metals was approximately 1.0-fold for SFG-Pu, approximately 1.1-fold for SFG-PuF 4 , and approximately 1.4fold for SFG- $\mathrm{PuO}_{2}$. The highest values of radiation damage come from $\mathrm{SFG}-\mathrm{PuO}_{2}$. The radiation damage criteria for structural material in the designed reactor system depend on the helium production limit. This drastically 
TABLE V

As in Table II, but for He-3.

\begin{tabular}{c|c|c|c}
\hline \hline \multirow{2}{*}{$\begin{array}{c}\text { Heavy metal } \\
\text { content [mol\%] }\end{array}$} & $\mathrm{He}-3$ production $(\mathrm{appm} / 30 \mathrm{FPY})$ \\
\cline { 2 - 4 } & $\mathrm{Pu}$ & $\mathrm{PuF}_{4}$ & $\mathrm{PuO}_{2}$ \\
\hline 1 & $2.709 \times 10^{-3}$ & $2.530 \times 10^{-3}$ & $2.772 \times 10^{-3}$ \\
2 & $2.391 \times 10^{-3}$ & $2.386 \times 10^{-3}$ & $2.635 \times 10^{-3}$ \\
3 & $2.338 \times 10^{-3}$ & $2.257 \times 10^{-3}$ & $2.135 \times 10^{-3}$ \\
4 & $2.335 \times 10^{-3}$ & $2.173 \times 10^{-3}$ & $2.066 \times 10^{-3}$ \\
5 & $2.313 \times 10^{-3}$ & $2.025 \times 10^{-3}$ & $2.021 \times 10^{-3}$
\end{tabular}

TABLE VI

As in Table II, but for He-4.

\begin{tabular}{c|c|c|c}
\hline \hline \multirow{2}{*}{$\begin{array}{c}\text { Heavy metal } \\
\text { content }[\mathrm{mol} \%]\end{array}$} & \multicolumn{3}{|c}{$\mathrm{He}-4$ production $(\mathrm{appm} / 30 \mathrm{FPY})$} \\
\cline { 2 - 4 } & $\mathrm{Pu}$ & $\mathrm{PuF}_{4}$ & $\mathrm{PuO}_{2}$ \\
\hline 1 & 76.25 & 74.75 & 89.68 \\
2 & 75.38 & 73.21 & 68.79 \\
3 & 75.34 & 71.38 & 68.67 \\
4 & 73.99 & 69.76 & 66.06 \\
5 & 73.85 & 66.76 & 64.59
\end{tabular}

reduces the lifetime of the reactor. The limit for helium production is suggested as 500 appm [12]. Table VI shows that the helium production limit was reached for the selected heavy metal contents. In Tables IV, V, this decrease in the tritium and He-3 production rates between the minimum and maximum contents of the heavy metals was approximately 1.2-fold for SFG-Pu and SFG$\mathrm{PuF}_{4}$ and approximately 1.4-fold for SFG-PuO 2 .

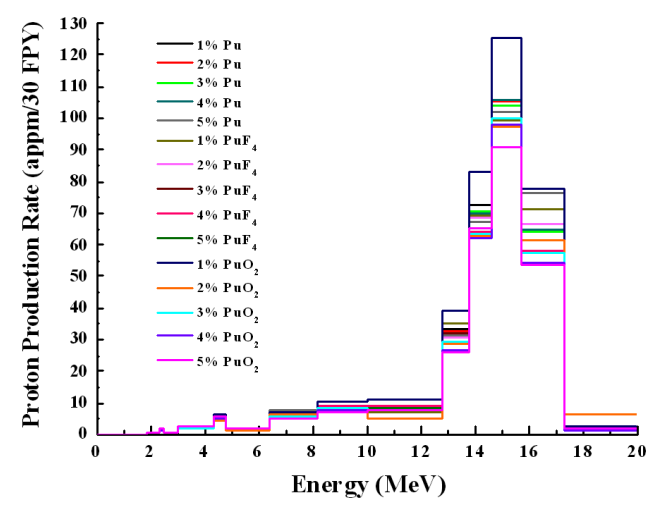

Fig. 1. The change of the proton production rate according to the neutron energy spectrum in the structural material for the selected fluids.

Figures 1-5 show the radiation damage parameters (appm/30 FPY) according to the neutron energy spectrum $(0-20 \mathrm{MeV})$ in the structural material for the selected fluid ratios. Figures 1-5 show that proton, deuterium, tritium, He-3 and He-4 gas production rates were greatest with $1 \% \mathrm{SFG}-\mathrm{PuO}_{2}$ and the lowest with $5 \% \mathrm{SFG}-\mathrm{PuO}_{2}$ heavy metal according to the energy in the structural material for other ratios and types of fluids.

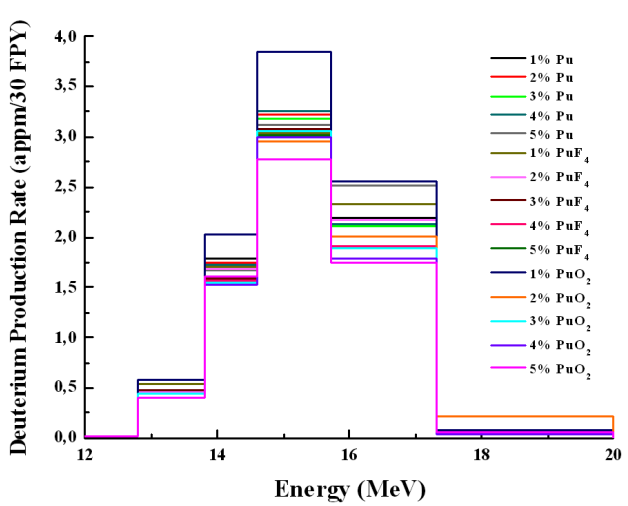

Fig. 2. As in Fig. 1, but for deuterium.

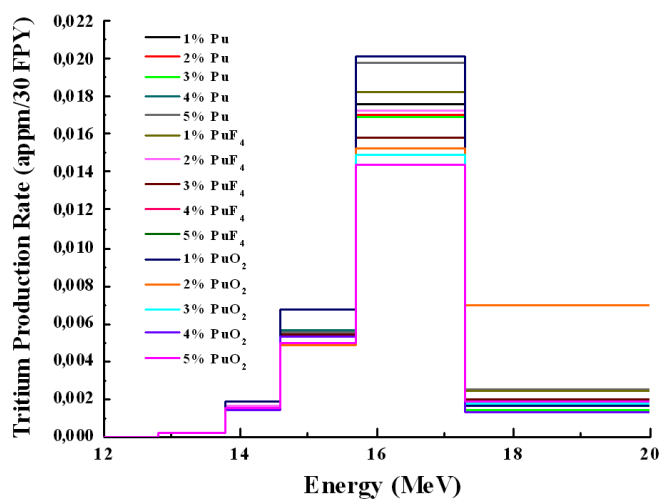

Fig. 3. As in Fig. 1, but for tritium.

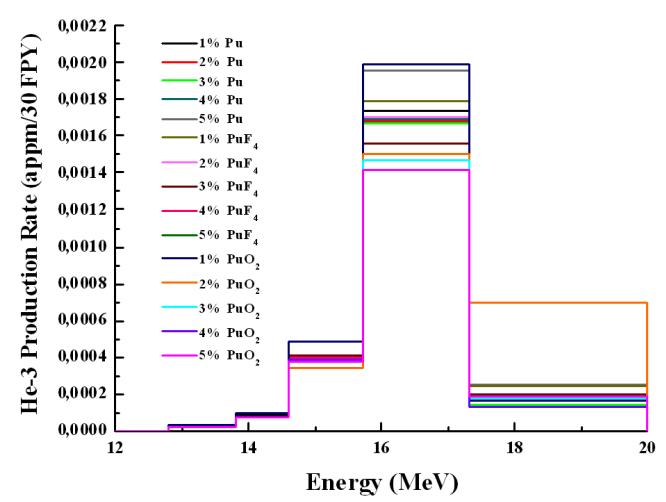

Fig. 4. As in Fig. 1, but for He-3.

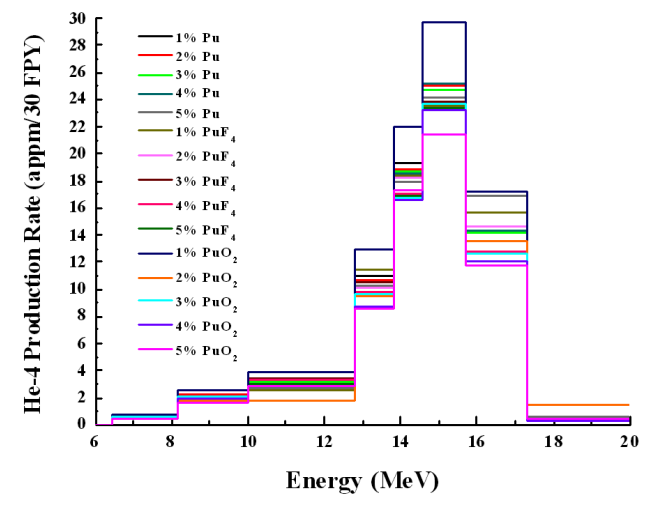

Fig. 5. As in Fig. 1, but for He-4. 


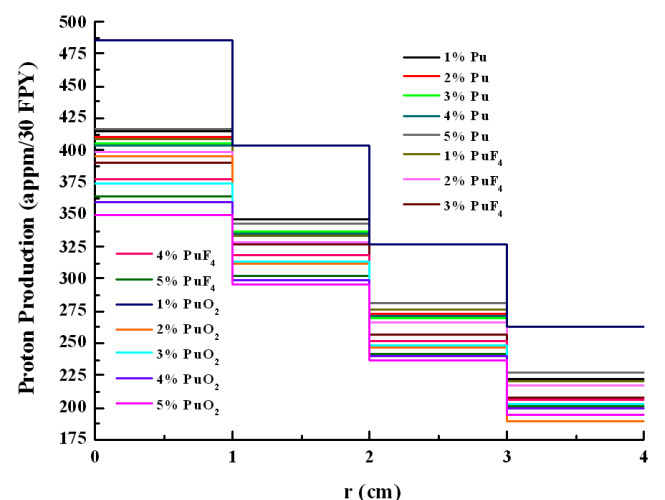

Fig. 6. Proton production in the structural material for each $1 \mathrm{~cm}$ structural material thickness for the selected fluids.

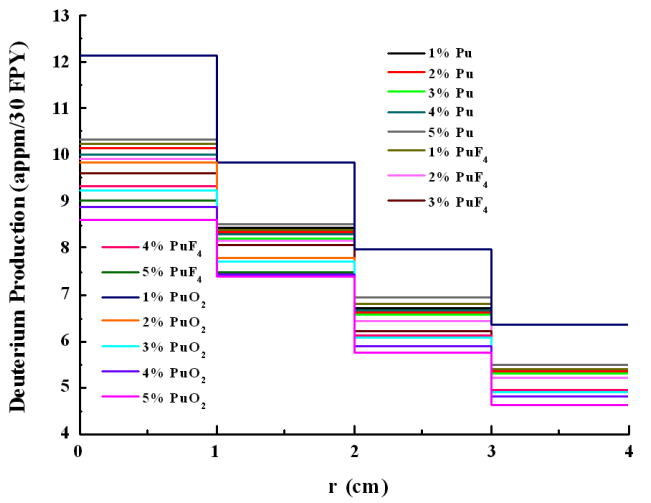

Fig. 7. As in Fig. 6, but for deuterium.

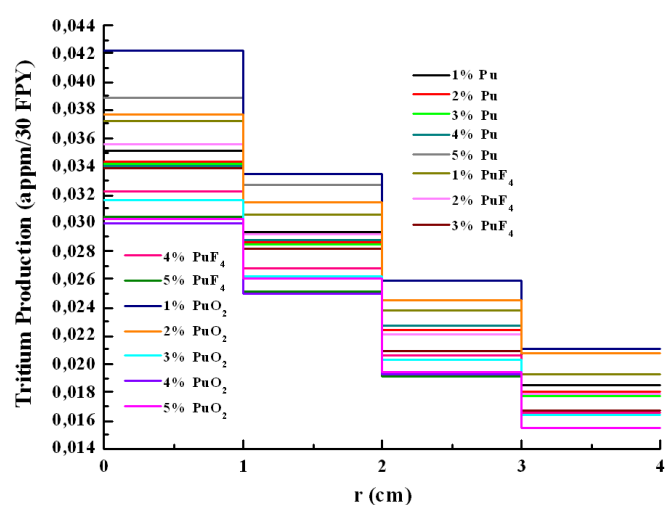

Fig. 8. As in Fig. 6, but for tritium.

Figures 6-10 show the radiation damage parameters (appm/30 FPY) for each $1.0 \mathrm{~cm}$ thickness of the structural material for the selected fluid ratios. The radiation damage parameters in the structural material decreased with each $1.0 \mathrm{~cm}$ of structural material thickness for the selected fluid ratios. This decrease between the minimum and maximum thicknesses of the structural material was

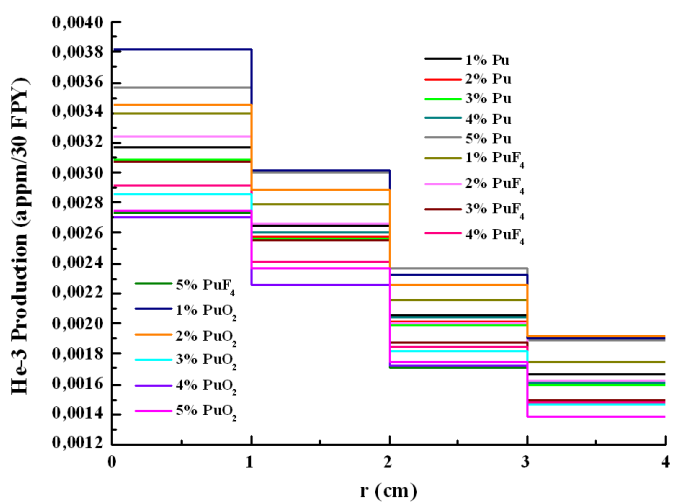

Fig. 9. As in Fig. 6, but for He-3.

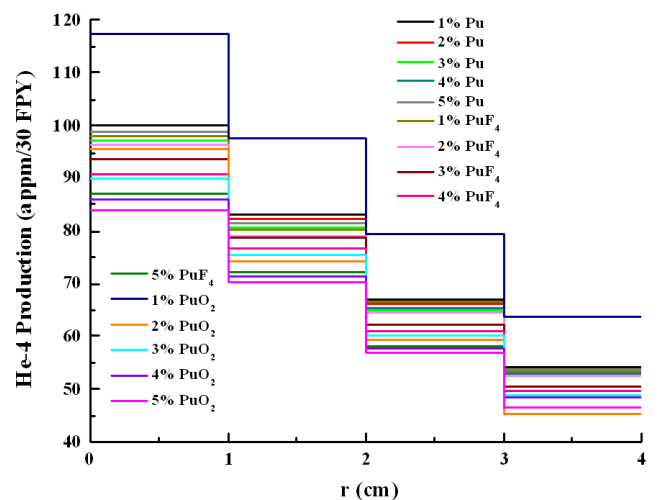

Fig. 10. As in Fig. 6, but for He-4.

approximately 1.9-fold for proton, deuterium, tritium, He-3 and He- 4 gas production. Figures 6-10 show that the proton, deuterium, tritium, $\mathrm{He}-3$ and $\mathrm{He}-4$ gas production rates were the greatest with $1 \%$ SFG-PuO $\mathrm{P}_{2}$ and the lowest with $5 \%$ SFG-PuO ${ }_{2}$ heavy metals.

A minimum of gas production is desired, because gas production reduces reactor life and accelerates deterioration of the structural material. In conclusion, the radiation damage parameters obtained according to the total and radial neutron energy spectra (0-20 MeV) in the structural material with $95 \% \quad \mathrm{Li}_{20} \mathrm{Sn}_{80}-5 \% \quad \mathrm{SFG}-\mathrm{PuO}{ }_{2}$ fluid showed the best performance of the fifteen tested fluids.

\section{References}

[1] S. Şahın, M. Übeyli, Energy Conv. Manag. 46, 3185 (2005).

[2] H.M. Şahın, Ann. Nucl. Energy 34, 861 (2007).

[3] B. Şarer, M. Günay, M.E. Korkmaz, A. Hançerlioğulları, Fusion Sci. Technol. 52, 107 (2007).

[4] M. Günay, B. Şarer, Y. Çelik, Ann. Nucl. Energy 38, 2757 (2011).

[5] IAEA, International Atomic Energy Agency, IAEATECDOC-1349, 2003. 
[6] M. Piera, A. Lafuente, A. Abánades, J. M. MartinezValet, Energy Conv. Manag. 51, 1758 (2010).

[7] A. Ying, K. Gulec, N. Morley, S. Smolentsev, M.Youssef, T. Sketchley, M. Abdou, B. Nelson, P. Fogarty, S. Zinkle, R. Moir, T. Rognlien, M. Resnink, D. Sze, H. Khater, J. Santarius, APEX Interim Report, Ch. 5: Thick Liquid Blanket Concept, 1999.

[8] B. Şarer, A. Aydın, M. Günay, M.E. Korkmaz, E. Tel, Ann. Nucl. Energy 36, 417 (2009).

[9] M. Günay, Ann. Nucl. Energy 53, 59 (2013).

[10] M.B. Chadwick, P. Oblozinsky, M. Herman, N.M. Greene, R.D. McKnight, D.L. Smith, P.G.Young, R.E. MacFarlane, G.M. Hale, S.C. Frankle, A.C. Kahler, T. Kawano, R.C. Little, D.G. Madland, P. Moller, R.D. Mosteller, P.R. Page, P. Talou, H. Trellue, M.C. White, W.B. Wilson, R. Arcilla, C.L. Dunford, S.F. Mughabghab, B. Pritychenko, D. Rochman, A.A. Sonzogni, C.R. Lubitz, T.H. Trumbull, J.P. Weinman, D.A. Brown, D.E. Cullen, D.P. Heinrichs, D.P. McNabb, H. Derrien, M.E. Dunn, N.M. Larson, L.C. Leal, A.D. Carlson, R.C. Block, J.B. Briggs, E.T. Cheng, H.C. Huria, M.L. Zerkle, K.S. Kozier, A. Courcelle, V. Pronyaev, S.C. Van der Marck, Nuclear Data Sheets 107, 2931 (2006).
[11] D.B. Pelowitz, MCNPX User's Manual, Version 2.7.0, LA-CP-11-00438, 2011.

[12] R.W. Moir, R.L. Bieri, X.M. Chen, T.J. Dolan, M.A. Hoffman, P.A. House, R.L. Leber, J.D. Lee, Y.T. Lee, J.C. Liu, G.R. Longhurst, W.R. Meier, P.F. Peterson, R.W. Petzoldt, V.E. Schrock, M.T. Tobin, W.H. Williams, Fusion Sci. Technol. 25, 5 (1994). 